Revue

d'ethnoécologie
Revue d'ethnoécologie

$13 \mid 2018$

Varia + Dossier "Anthropologie maritime"

\title{
La mujer y el mar en Cataluña
}

Realidad y representación

La femme et la mer en Catalogne : réalité et représentation

Women and sea in Catalonia: reality and representation

\section{Eliseu Carbonell}

\section{OpenEdition \\ Journals}

\section{Edición electrónica}

URL: http://journals.openedition.org/ethnoecologie/3517

DOI: 10.4000/ethnoecologie.3517

ISSN: 2267-2419

Editor

Laboratoire Eco-anthropologie et Ethnobiologie

\section{Referencia electrónica}

Eliseu Carbonell, « La mujer y el mar en Cataluña », Revue d'ethnoécologie [En ligne], 13 | 2018, mis en ligne le 25 juin 2018, consulté le 30 avril 2019. URL : http://journals.openedition.org/ ethnoecologie/3517; DOI : 10.4000/ethnoecologie.3517

Este documento fue generado automáticamente el 30 abril 2019.

\section{(c) (†) $\odot$}

Revue d'ethnoécologie est mis à disposition selon les termes de la licence Creative Commons Attribution - Pas d'Utilisation Commerciale - Pas de Modification 4.0 International. 


\title{
La mujer y el mar en Cataluña
}

\author{
Realidad y representación \\ La femme et la mer en Catalogne : réalité et représentation \\ Women and sea in Catalonia: reality and representation
}

\author{
Eliseu Carbonell
}

\section{Introducción}

1 En una intervención en el Parlamento Europeo, Maria Damanaki, entonces Comisaria Europea de Asuntos Marítimos y Pesca, ponía de manifiesto la existencia de « una contradicción inadmisible entre, por un lado, el papel que desempeñan (las mujeres en el sector marítimo y pesquero europeos) y la riqueza que generan y, por otro lado, entre su reconocimiento social y su falta de acceso a las prestaciones sociales $»^{1}$.

2 La falta de reconocimiento social del rol desempeñado por las mujeres en el ámbito marítimo-pesquero a la que se refería Damanaki tiene una larga historia. En Europa, las representaciones populares que nos hablan de la mujer en el ámbito marítimo, como tendremos ocasión de ver en este artículo, tienden a eludir el trabajo de la mujer en el sector pesquero y a limitarse a mostrar aspectos dramáticos que se desprenden de la inseguridad y la dureza de las condiciones de vida de las familias dedicadas a oficios del mar. A estas representaciones populares habría que añadir la discriminación de género en las comunidades asentadas en el litoral que, en el ámbito marítimo-pesquero, se podía constatar por ejemplo a través de la existencia de ciertos tabúes que impedían incluso el acceso de las mujeres a las embarcaciones, como mostró José Pascual (1991) para el caso de España o Michael Houseman (1990) para Francia.

En este artículo vamos a tratar sobre la representación tradicional de la mujer en el ámbito marítimo en Cataluña. Contrapondremos la representación, que nos ha llegado a través de la literatura y las artes plásticas, con las imágenes que podemos obtener procedentes de fuentes etnográficas, así como desde la fotografía. Observaremos, de este modo, un contraste muy marcado entre dos modelos opuestos. Por un lado, el de un rol pasivo atribuido a la mujer en el mundo social de la pesca, una mujer que contempla el 
destino, a menudo trágico, de su unidad familiar, sin poder hacer nada más que observar y sufrir en silencio. Pero por otro lado, hay otra imagen que se deriva de la información que podemos obtener a través de analizar las fotografías etnográficas y que concuerda mejor con el conocimiento histórico y etnológico de las comunidades tradicionales de pescadores en el sur de Europa. Estas fuentes nos muestran una imagen muy distinta de la mujer en el ámbito marítimo. Una imagen que nos habla de los múltiples e imprescindibles trabajos que desempeñaba la mujer en la pesca antes de la capitalización e industrialización de esta actividad. Ello concuerda mucho más con el concepto de " women-centered households » desarrollado por Sally Cole (1991) en su conocida monografía sobre una comunidad pesquera en Portugal.

4 A nivel histórico, las mujeres han desempeñado un papel muy relevante en las comunidades asentadas en el litoral, ocupándose de tareas específicas como la comercialización del pescado, la industria conservera o la reparación y fabricación de artes de pesca. También, aunque no vamos a ocuparnos de ello en este artículo, en la época de los grandes veleros para el comercio transatlántico con las colonias españolas de Cuba y Filipinas, en los siglos dieciocho y diecinueve, las mujeres comerciaban, actuaban en juicios, estaban inscritas en la Matrícula del Mar, llevaban sus casas y expedían, por su cuenta, mercancías a las colonias, como demostró Gabriela Dalla-Corte (1999) en su tesis doctoral.

5 En el primer apartado de este artículo vamos a presentar el marco teórico para el estudio del rol de las mujeres en las comunidades costeras, especialmente en Cataluña, que como hemos apuntado, era de fundamental importancia para el desarrollo de la actividad pesquera. Pero como han señalado varios investigadores, la capitalización de la actividad pesquera a partir de los años sesenta en adelante en España, habría provocado el progresivo abandono de gran parte de las actividades que hacían las mujeres, sacándolas del espacio público de la pesca. En cambio, en el espacio público han quedado otras imágenes de la mujer. Estas son las que vamos a analizar en el segundo apartado del artículo. Son las imágenes que transmiten las esculturas que decoran muchos paseos marítimos y que concuerdan con las imágenes que nos han llegado también a través de la literatura costumbrista. Estas imágenes, de todos modos, contrastan con otro tipo de imágenes que analizaremos en finalmente el tercer apartado. Son las imágenes que podemos ver en las fotografías, de hasta mediados del siglo veinte, donde aparecen mujeres vinculadas a la actividad pesquera. Estas imágenes concuerdan más con la información que se desprende de los textos etnográficos.

6 El objetivo de este artículo es contrastar estos dos tipos de imágenes, estableciendo un diálogo entre la realidad y la representación de la mujer en el ámbito marítimo en Cataluña.

\section{El estudio del género en el ámbito marítimo en Cataluña}

7 Tal y como puso de manifiesto una de las investigadoras pioneras en el ámbito de la antropología marítima como M. Estellie Smith (1977 : 4), muchas sociedades marítimas están caracterizadas por «un control femenino de la producción de los alimentos provenientes de la tierra; una mayor diferenciación de los roles de los hombres y las mujeres debido al punto anterior; y una independencia económica mayor para las 
mujeres ». Esto ha llevado en ocasiones a considerar que el rol de las mujeres era similar en todas las sociedades. Pero Jane Nadel-Klein y Dona Lee Davis (1988) matizaron que esto no era siempre así, sino que dependía de los contextos históricos, políticos, económicos y de la ideología de género que predominaba en cada sociedad en cada época. En este primer apartado del artículo nos centraremos en situar el rol de la mujer en las comunidades marítimas en Cataluña, a partir de repasar la literatura existente.

Hay que advertir que desafortunadamente esta literatura no es muy extensa, ya que las sociedades marítimas han sido poco atendidas hasta el día de hoy por parte de las Ciencias Sociales en el estado español donde, como señaló Marugán (2008), al androcentrismo se le ha añadido un cierto « urbanocentrismo » que ha perjudicado y retrasado aún más la comprensión del papel de las mujeres en las sociedades marítimas. Y sin embargo, ante la crisis del sector pesquero que se arrastra sobre todo desde la última década del siglo pasado, con el incremento de los costes de producción (precio del gasóleo, tasas, etc.) que ha ido en paralelo a la reducción de los beneficios (disminución de las capturas debido al agotamiento del recurso), las mujeres, señala Marugán (2008: 270), « han sabido reaccionar inventando múltiples estrategias para compensar el descenso de rentas familiares ». Esto pasa por la diversificación de la actividad profesional en las familias de pescadores, aprovechando por ejemplo la oportunidad que ofrece el turismo.

Uno de los primeros trabajos académicos de que disponemos centrados específicamente en las mujeres y la pesca en Cataluña, es un estudio publicado en 1992 por Françoise Breton, Fina Lladó y Anna Badia sobre el barrio marítimo barcelonés conocido como La Barceloneta. Estas autoras señalan un dato a tener en cuenta y es que la actividad de las mujeres dependerá del estatus de su marido o padre. En el caso de mujeres e hijas de patrón-armador y mecánico (que tienen respectivamente dos partes y una parte y media, en el reparto de las ganancias) consideraban que los hombres ya ganaban bastante y por lo tanto las mujeres no debían trabajar fuera del espacio doméstico. Por el contrario, las mujeres e hijas de los "remitgers", es decir, el resto de pescadores, necesitan trabajar fuera de casa para completar el salario familiar y los oficios que realizan a menudo están relacionados con el mundo pesquero, como puede ser la venta de pescado o como cocineras, camareras o limpiadoras en los diversos restaurantes que hay en el barrio de la Barceloneta, tradicionalmente un barrio popular con muchos restaurantes de buena comida marinera. A menudo estos trabajos no están declarados, forman parte de la economía sumergida.

10 Se trata pues de una generación todavía muy ligada a los valores tradicionales de la domesticidad y el patriarcado que el régimen franquista, con la ayuda de la Iglesia católica, impusieron en España y que perduraron bastante más allá de la llegada de la democracia en 1978. Entre las investigaciones en Cataluña que se centran directamente el estudio del rol de las mujeres en el ámbito marítimo podemos citar las de Breton, Lladó y Badía (1992), Benavent (1993), Dalla-Corte (1998), Alberich (2001), Comes (2009), Pujol y Carbonell (2009), Torra y Carbonell (2015).

11 Para la comprensión y explicación del papel de las mujeres en las sociedades marítimas tradicionales debemos prevenirnos ante el riesgo epistemológico que supone el actualismo. El proceso de distinción entre la pesca artesanal y la pesca industrial acontecido en Cataluña durante los años setenta del siglo pasado, en un contexto de fuerte industrialización y modernización general del país, se introdujeron cambios muy importantes y significativos en las estrategias económicas de las familias dedicadas la 
pesca que han afectado muy particularmente al papel de las mujeres en el conjunto de estas sociedades. Esto implica pues una diferenciación importante a tener en cuenta.

En el mundo de la pesca en Cataluña y en España, lo más habitual es que las mujeres realicen los trabajos de tierra. Algunas de estas actividades son fundamentales para la subsistencia, como la recolección de crustáceos, salar, secar y ahumar pescado, su comercialización, etc. Según apunta Cáceres (1999), el avance del capitalismo en la industria pesquera habría provocado el abandono de gran parte de las actividades que hacían las mujeres, confinándolas al ámbito doméstico, durante el último tercio del siglo veinte.

Esto es importante tenerlo en cuenta, porque significaría que la retirada de las mujeres del espacio público para realizar actividades productivas y comerciales en las sociedades tradicionales pesqueras se habría producido a partir de los años setenta en que precisamente en España las mujeres comienzan a llegar a este espacio público en otros ámbitos como la política, la empresa o la universidad. Significa también que la imagen que tenemos de las mujeres en las sociedades pesqueras de los años sesenta y setenta no se corresponde con la anterior a la de la llegada del capitalismo en estas sociedades. Así, por ejemplo para el caso de las vendedoras de sardinas en el País Vasco, las famosas " sardineras de Santurce ", Rúbio-Ardanaz indica que:

«en el ámbito de las sociedades tradicionales del mundo arrantzale, la mujer aparece ocupando un lugar importante, ejerciendo unos roles y unas tareas muy concretas en el proceso de producción. Se muestra en este como con un espacio determinado, participando con sus trabajos en el entramado sociocultural de la pesca. Es así como la sardinera desarrolló un papel clave en el momento de la distribución del pescado, rol económico que ha sufrido una marginación y sustitución progresiva por otros medios de venta » (Rubio-Ardanaz 2011 : 286).

Otra cosa distinta es si hablamos estrictamente de la actividad propiamente de extractiva de la pesca. En Cataluña resulta muy raro, aunque no imposible, encontrar una mujer embarcada en un barco de pesca. Sólo se encuentran algunas, de forma esporádica, embarcadas con sus maridos, padres o hermanos en pequeñas embarcaciones artesanales de propiedad familiar. Alegret (1987) explicaba que en Palamós en los años ochenta sólo había una mujer que excepcionalmente salía a pescar con su padre pero que lo dejó tan pronto como encontró otro trabajo. Alberich (2001) sólo encontró una mujer que salía a pescar en Cambrils en los años noventa. También Benavent (1993) informa que en Vilanova a comienzos de los años noventa sólo había una mujer pescadora. En la misma época Breton, Lladó y Badía (1992) nos dicen que en Barcelona no había ninguna mujer pescando, aunque la gente recordaba que años atrás había habido una que salía a pescar con su hijo. Más recientemente, en mi trabajo de campo en la costa catalana he podido constatar la misma situación. Por ejemplo, un pescador de L'Estartit nos explicó que algunos pescadores que tienen la barca de más de siete metros de eslora, como que por ley deben ir dos personas, tienen su mujer enrolada, aunque en realidad no vaya nunca con él a pescar. También en una barca de arrastre de El Port de la Selva gestionada por unos hermanos, me contaron como algo muy excepcional que uno de los hermanos era una chica. Pero realmente todavía es visto como algo muy excepcional. Finalmente, en el puerto de Arenys actualmente hemos encontrado dos mujeres embarcadas, las dos salen a pescar con sus maridos en embarcaciones artesanales (Torra \& Carbonell 2015 : 99-105).

Por tanto, las tareas más frecuentemente desarrolladas por las mujeres en relación a la pesca, según puede deducirse de las etnografías consultadas, son las relacionadas con actividades terrestres tales como: Fabricación y reparación de redes; Limpieza de 
utensilios de pesca y embarcaciones; Recolección de cebo para la pesca; Descarga y transporte de pescado; Suministros de agua para la limpieza del pescado; Venta de pescado a pequeña escala; Transformación y conservación de producción pesquera.

Todas estas tareas tienen una gran trascendencia económica en las comunidades de pescadores catalanes y no pueden ser calificadas de auxiliares, tal y como algunos etnólogos de principios de siglo veinte intentaron hacernos creer (Roig 1927 : 23). Son tareas tan importantes como las que realizan los hombres en los barcos de pesca en alta mar. Pero quedaría bastante claro, tal y como ya dijo Alegret (1987), que la división sexual del trabajo afecta muy claramente en el medio, es también una división geográfica: la tierra es el espacio geográfico de las mujeres y el mar de los hombres, mientras que la línea de frontera estaría en los puertos donde conviven hombres y mujeres y hacen trabajos compartidos (Alegret $1987: 204$ ).

En esta franja costera, sin embargo, encontramos otras figuras femeninas que impactan de manera importante en el imaginario social sobre la mujer y el mar. Nos referimos a las múltiples esculturas que decoran muelles y paseos marítimos, donde aparece la imagen de una mujer, a menudo una madre, que mira con rostro grave hacia el horizonte marino. Las imágenes culturales sobre la mujer y el mar van más allá de la realidad social registrada en las etnografías. Entramos en el terreno de la representación que se ha transmitido en el imaginario colectivo a través, por ejemplo, de esculturas, pero también a través del cancionero popular, la poesía, el teatro, la novela y los cuentos populares. En los siguientes apartados repasaremos estas representaciones sobre la mujer y el mar en la cultura catalana, fijándonos en dos imágenes contrapuestas: la mujer que espera y la mujer que actúa.

\section{La mujer que espera: la representación cultural de un rol pasivo.}

Pensar en el hombre y el mar a menudo nos lleva a imaginar un pescador trabajando en la cubierta de una barca o un marinero en alta mar agarrando fuertemente el timón. Cuando pensamos en la mujer y el mar, en cambio, nos aparece con facilidad la imagen de una mujer parada frente al mar, contemplando el horizonte. Es una mujer que espera que vuelva la barca de su marido o padre. Una mujer que espera sola o rodeada de niños pequeños. Una mujer que a veces está tranquila y otras veces angustiada. Esta no es una imagen particular de la cultura catalana. La imagen, más o menos dramática, de la mujer que espera un hombre que debe volver por el mar, la encontramos en Occidente en muchas pinturas y esculturas, poemas y novelas.

La primera imagen que evocamos aquí proviene del pintor catalán probablemente más universal, Salvador Dalí, que en 1925 pintó a su hermana de espaldas mirando por una ventana frente a la bahía de Cadaqués. En este cuadro, conocido como «Figura en una ventana $»^{2}$, toma mucha fuerza la idea de la contemplación, de espera serena. Una chica que mira al mar sosegadamente. Es una imagen que nos evoca buen tiempo, mar en calma dentro de la bahía, aire tibio, ropa limpia. Es una imagen de un cierto confort.

Pero esta imagen apacible del gran pintor ampurdanés es más bien excepcional. La podemos contraponer a la imagen popular de otras mujeres que esperan con más desazón o dramatismo. Nos referimos a las imágenes de mujeres que esperan el regreso de sus 
seres amados, con angustia, ante un mar tempestuoso y que vamos a encontrar en muchas representaciones plásticas y literarias.

21 En efecto, en los pueblos del litoral catalán encontramos numerosas esculturas que representan una mujer en esta actitud que acabamos de describir. Una de ellas es el monumento a la « Mujer marinera » (Figura 1), escultura en bronce del escultor Ernest Maragall inaugurada en 1966, que se puede contemplar el final de la playa de Lloret de Mar. Aquí la mujer es «marinera » no por la actitud de pilotar un navío sino porque espera la llegada de un marinero. Parece que con el brazo quisiera tapar el brillo del sol para poder mirar mejor al mar.

Figura 1 : Mujer Marinera

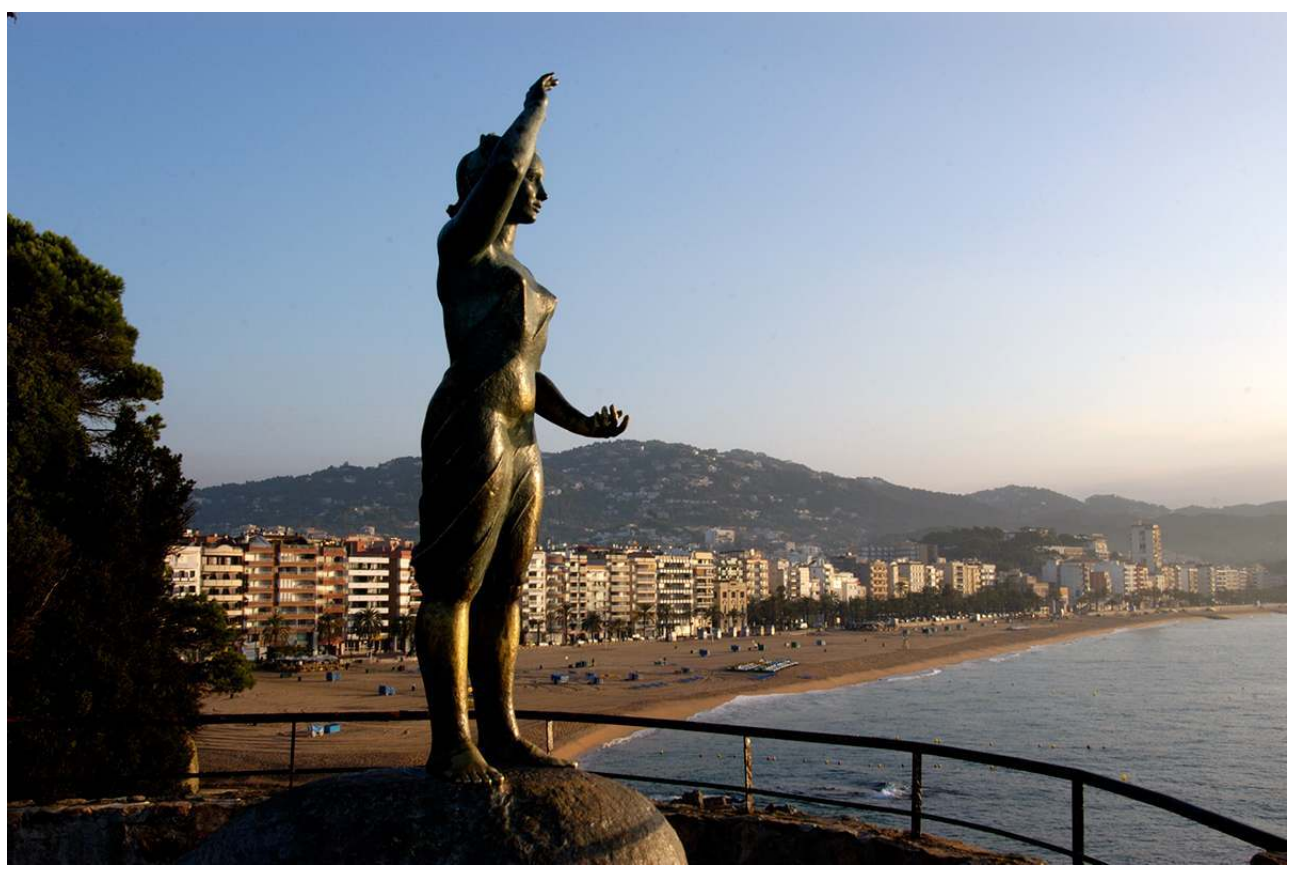

FOTO: ÁREA DE PATRIMONIO CULTURAL DEL AYUNTAMIENTO DE LLORET DE MAR

No muy lejos de allí encontramos el monumento en homenaje a la actriz Ava Gardner, en Tossa de Mar (Figura 2), inaugurada en 1998. La escultura nos muestra la actriz en la misma actitud quieta y contemplativa hacia el mar. Esta escultura quiere ser un recuerdo del rodaje de la película Pandora and the Flying Dutchman (1951), « que proyectó Tossa y la Costa Brava al mundo » según se lee en la inscripción al pie del monumento. Al igual que el personaje de Pandora de la película, la estatua parece contemplar el mar de donde le llegará su destino trágico. 
Figura 2 : Monumento a Ava Gardner

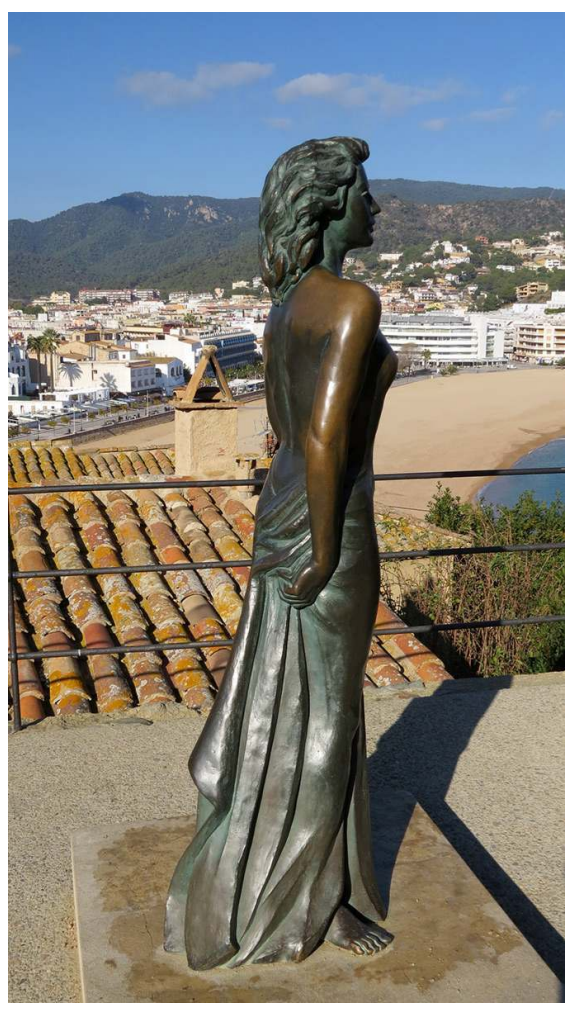

FOTO: ÁREA DE PATRIMONIO DEL AYUNTAMIENTO DE TOSSA DE MAR

Por citar un último ejemplo, en L'Escala, encontraremos un « Monumento a la mujer del pescador » (Figura 3) promovido por la Cofradía de Pescadores, realizado por el escultor Francesc Xavier Vila e inaugurado en 1991. Este monumento consiste en una figura de bronce que representa a una mujer con dos niños, uno agarrado a sus piernas, y otra criatura más pequeñita en brazos de su madre. La mujer lleva la cabeza cubierta por un pañuelo que ondea al viento y tiene la mirada grave fijada hacia el horizonte marino. 
Figura 3 : Monumento a la mujer del pescador. L'Escala

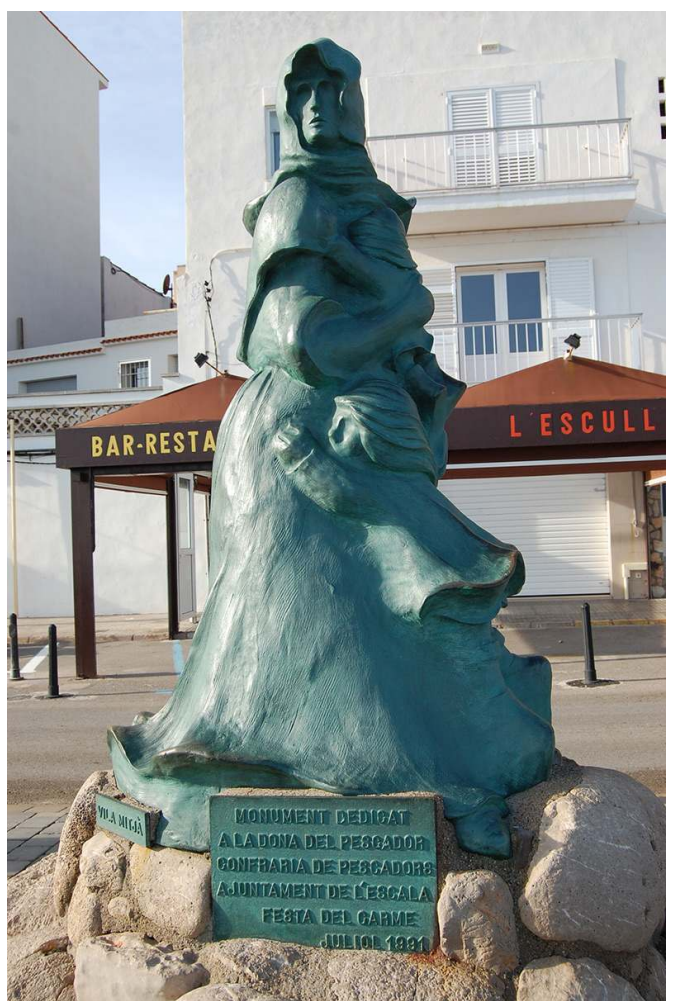

FOTO: E. CARBONELL

Esta imagen recuerda mucho una postal publicada en el libro Els premianencs i el mar (Sol \& Jiménez 2005) y que reproducimos en la Figura 4. En la postal aparecen sobre la playa, frente a un mar alborotado con altas olas, una mujer con el pañuelo en la cabeza que sostiene un bebé en su brazo derecho y da la mano a otra criatura pequeña que, como la madre, contempla angustiada el horizonte. Detrás se ven en perspectiva, más alejadas, otras figuras humanas que caminan por la playa, se puede distinguir otra madre con un hijo de la mano y al fondo una chimenea humeante. Es uno de los pocos ejemplos iconográficos en Cataluña de principios del siglo veinte en que se vincula pesca con industrialismo. 
Figura 4 : Postal conmemorativa del temporal de 1911

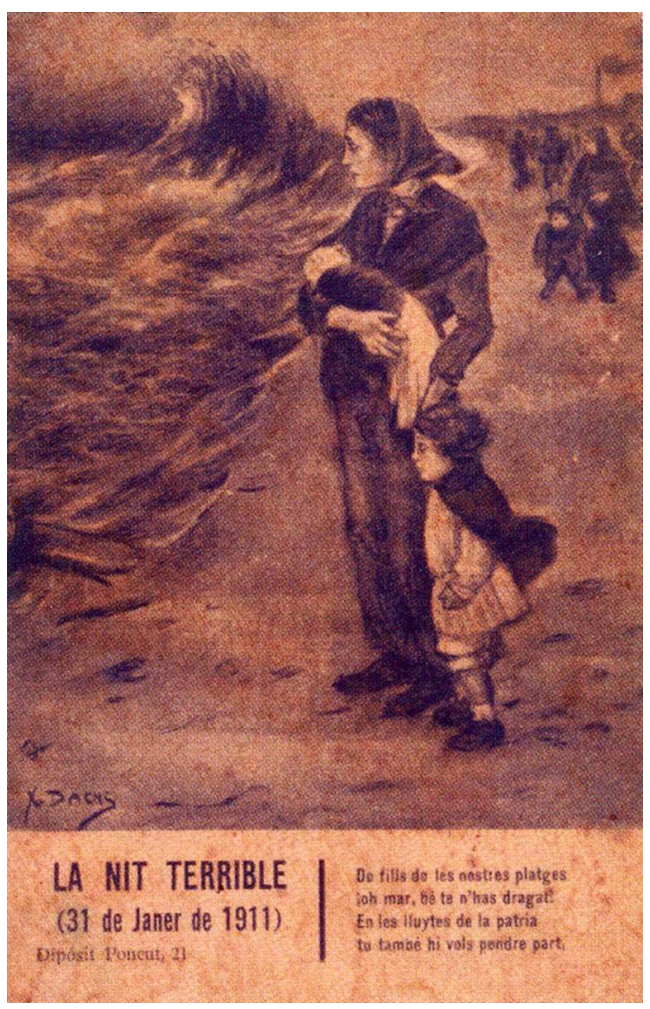

FOTO: SOL \& JIMÉNEZ (2005 : 107)

La postal se titula al pie "La noche terrible » y hace referencia al temporal marítimo en que murieron 140 marineros y pescadores en las costas catalanas la noche del 31 de enero de 1911 (Carbonell 2012). La postal se realizó con el objetivo de recolectar donativos para las familias de los que murieron ahogados. Joan Sol comenta con acierto esta postal diciendo que «expresa la fatalidad con que se vivió el desastre, en unos tiempos convulsos y de gran conflictividad social, como los que afectaban al mundo obrero a principios del siglo veinte » (Sol \& Jiménez 2005 : 107). En efecto, a menudo se ha reducido el sufrimiento de la gente de mar a la dureza del medio en el que tenían que desarrollar sus tareas. Pero tal y como han puesto de manifiesto autores como William Torry (1972) o más recientemente Frida Hastrup (2011), los desastres naturales no pueden ser meramente interpretados como unos accidentes que vienen a turbar la estabilidad social sino que en cierto modo son la culminación de un sistema de desigualdades sociales que se expresa también en los niveles de vulnerabilidad ante las catástrofes naturales.

Estas representaciones pictóricas y escultóricas tienen también su equivalente literario, tanto en la literatura catalana como en otras literaturas. Nos centraremos brevemente en el caso de la literatura catalana costumbrista característica de los primeros decenios del siglo veinte.

En la literatura naturalista marinera, de autores como Joaquim Ruyra (1858-1939), Ignasi Iglésias (1871-1928), Àngel Guimerà (1845-1924) o Josep Maria de Segarra (1894-1961), entre otros, la mujer no tiene realmente un papel muy activo. No hace falta recordar que todos estos escritores eran hombres. En El rem del trenta de trenta-quatre (1904), una de las narraciones más conocidas de Ruyra, las reticencias del patrón a embarcar a su hija se demuestran justificadas por la terrible tormenta que se desata la primera noche de la 
travesía. En La barca nova (1907) de Iglésias los personajes femeninos están rodeados también de un halo de tragedia. En las obras de Guimerà o Segarra las mujeres ocupan ese espacio junto al mar, esperando su oportunidad para interactuar en una sociedad donde los hombres se embarcan y desembarcan diariamente. De todos modos, podemos encontrar fragmentos, en estas narraciones, que aportan información interesante acerca de cómo los escritores veían a las mujeres de su tiempo en las comunidades marítimas. Debemos citar aquí, por ejemplo, la narración Mar del llamp (1903) de Ruyra, donde la gente del pueblo, sobre todo las mujeres, están en la orilla del agua contemplando el temporal. Las lágrimas se confunden con las salpicaduras del mar y las gotas de lluvia, mientras esperan ver unas barcas que ya no volverán. Una escena similar la encontramos también en la narración Mànigues marineres (1903) del mismo autor. Ruyra muestra una gran habilidad para describir las tormentas, pero también los sentimientos y la angustia de los personajes femeninos agrupados en el puerto observando el desarrollo de la tormenta:

«Vaig sentir un gemec a prop meu. L'havia esclafit aquella dona que poca estona abans m'havia parlat de que tenia a mar tota la seva família. Estava immòbil, estirada, com enravenada de fred, pàllida, amb els ulls astorats. El cap li tremolava lleument $\mathrm{i}$ les dents li debategaven. Sos llavis descolorits repetien un mot, sempre el mateix: Menut... menut meu! »3 (Ruyra 2004 : 66).

Otro ejemplo significativo lo encontramos en el último de los grandes escritores del naturalismo rural catalán que nos describió el mar y el litoral, aunque ya plenamente insertado en la tradición literaria contemporánea, el ampurdanés Josep Pla ${ }^{4}$ (1897-1981). En el libro Cadaqués (1947), donde encontraremos algunas de las mejores descripciones mar de su literatura, Josep Pla narra la pérdida de una embarcación de esta población acaecida un día verano de finales del siglo diecinueve. El bergantín Gabriela, matrícula de Cadaqués, zarpó con despacho para Italia. Salió de la bahía a remos. Las velas colgaban flácidas en ausencia total de viento. Fueron pasando las horas y al caer la tarde el bergantín encendió las luces de posición que pudieron ser vistas desde el pueblo toda la noche. A la mañana siguiente, la esposa de uno de los marineros embarcados en el Gabriela subió a un punto panorámico desde donde se dominaba el horizonte marino para ver el barco y se quedó allí sin moverse, sentada sobre una roca, hasta que la niebla envolvió el navío y desapareció de la vista.

La narración sigue adelante, explicándonos que la calma y la calima duraron aún dos días más hasta que al fin entró un viento de suroeste muy conveniente para velejar hacia Italia. Pero iban pasando los días y las semanas y no se recibían noticias del bergantín. «Començà una angoixa general que desembocà en una tragedia obscura »5 (Pla 1947 : 162). Se llevaron a cabo todo tipo de indagaciones que resultaron infructuosas. No había llegado a su destino ni ninguna otra nave la había visto en mar. Nunca más se supo nada del barco ni de las vidas humanas que transportaba. La mujer del marinero que pasó el día contemplando el horizonte marino con su pañuelo negro cubriéndole el pelo fue la última persona que vio el bergantín hasta que fue engullido por la calima bochornosa de la canícula. Aunque se especuló sobre la posibilidad de un abordaje y hundimiento, nunca se pudo demostrar ni ésta ni ninguna otra teoría. Era como si el Gabriela se hubiera fundido en la bruma.

¿Qué más podía hacer aquella mujer aparte de mirar desde una peña cómo la nave donde viajaba su marido se alejaba en el horizonte a merced del destino? Es como si el peso del destino cayera encima de las mujeres de los marineros que no pueden luchar contra él ni hacer nada para cambiarlo. Es como si una impotencia, una incapacidad de acción, las 
mantuviera atadas de manos y pies, inmóviles como esculturas de bronce. Esta es una imagen cultural, es importante subrayarlo. Lo que queremos decir es que esto es una representación cultural, que no tiene por qué coincidir con la historia y la etnología de los pueblos y, en definitiva, con la vida social de las mujeres en las sociedades marítimas.

Existen cuentos populares con diferentes versiones en diferentes países europeos, y que encontramos también en Cataluña (Soler 1996), donde la joven que espera el barco de su amado se convierte, debido a la intensidad de los sentimientos de la espera, no en estatua de bronce, sino en un árbol plantado junto del mar. Estos cuentos están inspirados en Filis, un personaje femenino de la mitología griega que se convirtió en un almendro. Es una imagen de constancia en el amor, de arraigo junto al mar, y también de un rol más o menos pasivo de la mujer. El hombre es el que se embarca en las aventuras, a buscar -el alimento, la fortuna, la aventura, la guerra- mientras la mujer espera su retorno desde el ámbito del pueblo, la casa, la familia... la imagen del árbol, que arraiga y no se mueve de lugar, vehicula bien este significado. De este cuento popular existen como hemos dicho numerosas versiones. El poeta mallorquín Gabriel Janer Manila, sintetizó esta historia en una canción interpretada por la cantautora, también mallorquina, Maria del Mar Bonet ${ }^{6}$.

La mujer que espera puede tener este final mítico, pero también puede acabar enloquecida por la fuerza de la desesperación. Aquí aparece la locura y también el suicidio. Un impresionante poema del mallorquín Miquel Costa i Llobera (1844-1922), uno de los máximos representantes del romanticismo literario en lengua catalana, titulado Cançó de Na Ruixa-mantells, musicado también por Maria del Mar Bonet ${ }^{7}$, nos habla del proceso de locura de una mujer, entre acantilados al borde del mar, que sabe que su amado ya está perdido en el mar:

« La mar jo avorria mes ja l'estim ara / des que hi té l'estatge l'amor que em fugí. /

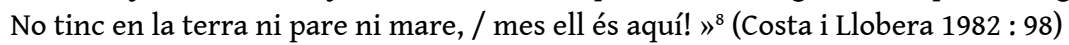

Otra historia donde aparece la locura de una mujer y su suicidio en unos acantilados junto al mar es la novela Jacobé de Joaquim Ruyra, publicada en 1903. En esta historia, el progresivo deterioro mental de la hermana de leche del protagonista (es decir, la hija de su nodriza) acaba fusionándose simbólicamente con los perfiles abruptos de la Costa Brava, y la combinación de mar y locura explican el desenlace final.

En el libro Cadaqués (1947) de Josep Pla, al que nos hemos referido antes, la tragedia de las mujeres en las familias de pescadores la encontramos representada en otra narración donde el escritor cuenta la historia del suicidio de Aurora, acontecido en Cadaqués el año 1922. La familia de Aurora eran unos pescadores muy pobres, como tantos pescadores de la costa catalana en aquellos años. Ella decide romper con su destino marchando de noche, a escondidas de su familia, a las fiestas del pueblo vecino de Castelló d'Empúries acompañada de un joven que no es pescador sino electricista. La pareja trata de propiciar un «matrimonio por fuga », modalidad de matrimonio consuetudinario practicado en la España rural, tal como mostró Joan Frigolé (1999). Pero en esta ocasión no lo consiguieron. La fuga es interpretada por la familia como una gran ofensa y causante de un gran deshonor para la familia. La presión social llega a ser tan insoportable que la joven Aurora cree que la única opción que le queda es el suicidio.

35 Con temporal o en calma, el mar nos aparece en la literatura catalana como fuente de interminables tristezas para las mujeres. En el volumen titulado Notes disperses, Josep Pla concluye:

« En aquestes vores del Mediterrani les noies, fins i tot quan riuen, tenen una punta

de neguit i de tristesa $»^{9}$ (Pla $\left.1969: 20\right)$. 


\section{La mujer que actúa: la imagen que transmiten las fotografías}

A esta imagen de la mujer triste, angustiada, expectante, que acabamos de ver descrita a través de representaciones plásticas y en la literatura, se puede y se debe contraponer otra imagen: la de la mujer sonriente, más relajada, ocupada por la tarea que tiene entre manos. No es una mujer que contempla pasivamente sino una mujer que actúa. Esta es, por ejemplo, la imagen que nos transmiten muchas de las fotografías que encontramos en álbumes familiares o bien realizadas por fotógrafos profesionales y etnógrafos que recorrieron la costa catalana. Por ejemplo, en la figura 5 podemos ver a una reparadora de redes, Esther Pujol, una mujer de Sant Pol de Mar nacida en 1921, a la que tuve la fortuna de hacerle una historia de vida y publicarla juntos (Pujol \& Carbonell 2009), retratada en su juventud, sentada sobre la arena de la playa, con la red delicada entre sus dedos y una gran sonrisa dibujada en su rostro.

Figura 5 : Esther Pujol reparando una red de sardinal en la playa de Sant Pol de Mar en 1941

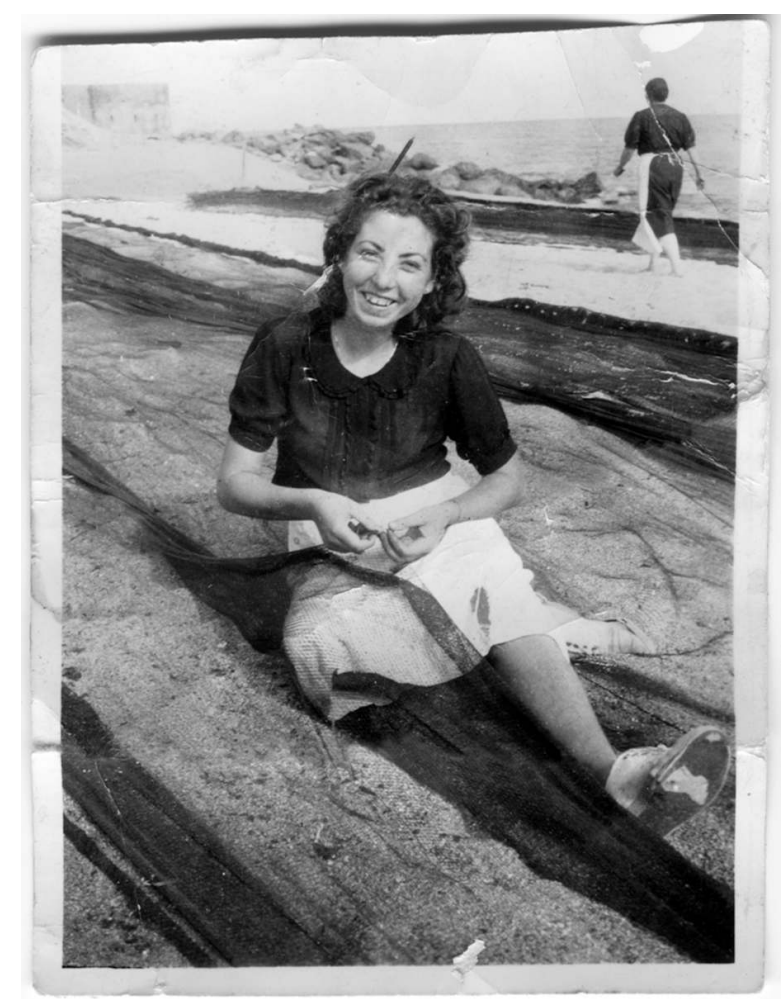

FOTO: FAMILIA VIVES-PUJOL, COLECCIÓN PRIVADA.

Curiosamente, encontramos otra imagen similar de otra mujer joven, trabajadora del mundo de la pesca y que mira la cámara con una generosa sonrisa. La foto fue realizada durante una de las pocas expediciones etnográficas de esta temática que se hicieron Cataluña en la primera mitad del siglo veinte (Figura 6). Se trata de una fotografía del etnólogo catalán Tomás Carreras i Artau (1879-1954), tomada en 1922. 


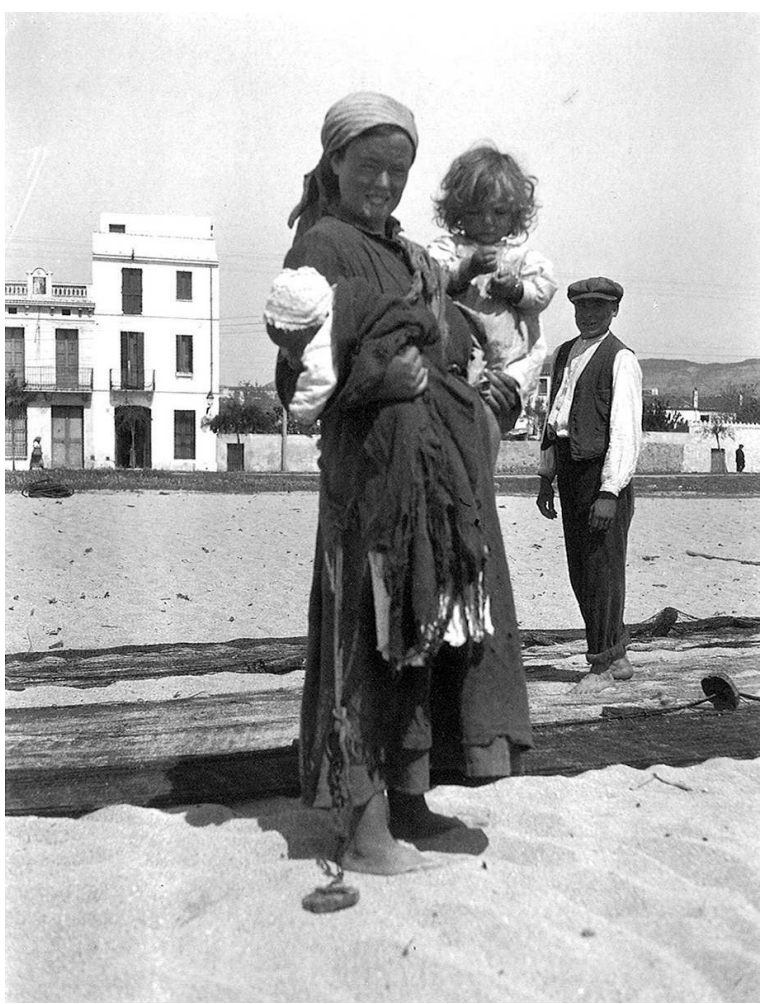

FOTO: TOMÀS CARRERA I ARTAU. ARCHIVO: INSTITUCIÓ MILÀ I FONTANALS (CSIC), BARCELONA

4

\begin{abstract}
« Una 'tiradora', hija del pueblo de Pinto, cerca de Madrid. Nótese que lleva todavía el estrobo. Está casada, y su marido también tira del arte: le he visto. Va ella con 2 pequeños (fotografía casi espontánea). El pequeño no tiene ni un mes, y nótese que ella acaba de trabajar. De día y de madrugada lo tiene en la arena, y le da de mamar » (Calvo, Mañá \& Naranjo 1994: 73).
\end{abstract}

Las mujeres que trabajaban en la playa asumían un papel que permitía a la unidad doméstica aumentar los ingresos y reducir los gastos. Esto les proporcionaba relevancia social. Es interesante observar las tres imágenes (Figuras 3, 4 y 6) conjuntamente. Estas imágenes -una escultura, un dibujo y una fotografía- reproducen la misma escena, una mujer de mar con dos niños pequeños, el pañuelo en la cabeza, erguidas cerca de las olas del mar. Pero la imagen y el mensaje que transmiten son muy diferentes. encontramos en narraciones, canciones e representaciones plásticas), hay que reivindicarla. Las mujeres que trabajan siempre han existido, a pesar de que su trabajo haya sido muy a menudo invisibilizado. Incluso cuando la mujer entra a trabajar en espacios fuera del ámbito doméstico a menudo queda engullida por las generalizaciones masculinas del trabajo. Es por este motivo que es interesante fijarnos con más detalle en los significados que ofrece esta imagen.
La imagen de la mujer que trabaja, que actúa, es también una imagen importante a reivindicar. Si bien no ha sido tan reificada en el imaginario cultural (es decir, apenas la Fijémonos en que la imagen de la reparadora de redes de la playa de Sant Pol (Figura 5) o de la tiradora del arte de la playa de Badalona (Figura 6). Presentan una diferencia significativa respecto a las imágenes analizadas en el apartado anterior. Son mujeres que 
no están esperando a ningún hombre. Su presencia en la playa se explica por motivos que las incumben sólo a ellas. Son mujeres que podemos observar en ellas mismas, liberadas del vínculo evidente con el hombre que está mar adentro y que tan claramente podíamos percibir en la mujer que espera.

Podemos continuar explorando estos lazos de amor y parentesco y fijarnos en la presencia de los niños. En la serie de tres imágenes que acabamos de presentar, cada una de las mujeres lleva un bebé en brazos y tiene un niño o una niña pequeños agarrados a su vestido o en brazos también. La aparición de los niños en estas imágenes tiene claramente su propio significado. En primer lugar, sitúa estas mujeres en la categoría de madres. No estamos observando mujeres jóvenes, libres, sin ataduras, sino mujeres que tienen a su cargo unos niños a los que cuidar y seguramente un hogar que hay que sacar adelante. Son personas con responsabilidades sociales y familiares.

En este contexto, la figura de un hombre que complete la estructura doméstica y aporte comida a casa es indispensable. Estas mujeres que miran angustiadas al mar con los hijos a su alrededor no sólo sufren por amor, sino también por la supervivencia del grupo doméstico, principalmente de los menores. Desgraciadamente, es un hecho constatable que en los hogares pescadores en que se quedaban huérfanos de padre, la miseria y la mortalidad aumentaban de forma exponencial. Paul Thompson (1985) mostró que en el este de Inglaterra la mortalidad infantil de las familias dedicadas a oficios marineros doblaba a la de los oficios terrestres. Esto se agravaba mucho más si desaparecía el hombre y quedaba la mujer sola como responsable de la supervivencia de los niños. De esta tragedia se han escrito páginas universales, bastará con recordar el gran poema de Victor Hugo titulado «Les pauvres gens» que relata de forma magistral esta estremecedora realidad.

Podemos ahora ampliar el foco y mostrar dos fotografías (Figuras 7 y 8 ) realizadas por el fotógrafo Francesc Llorens en la década de 1930. En las fotos podemos ver mujeres en la playa, rodeadas de su familia.

Figura 7 : Mujeres en la playa de Somorrostro (Barcelona)

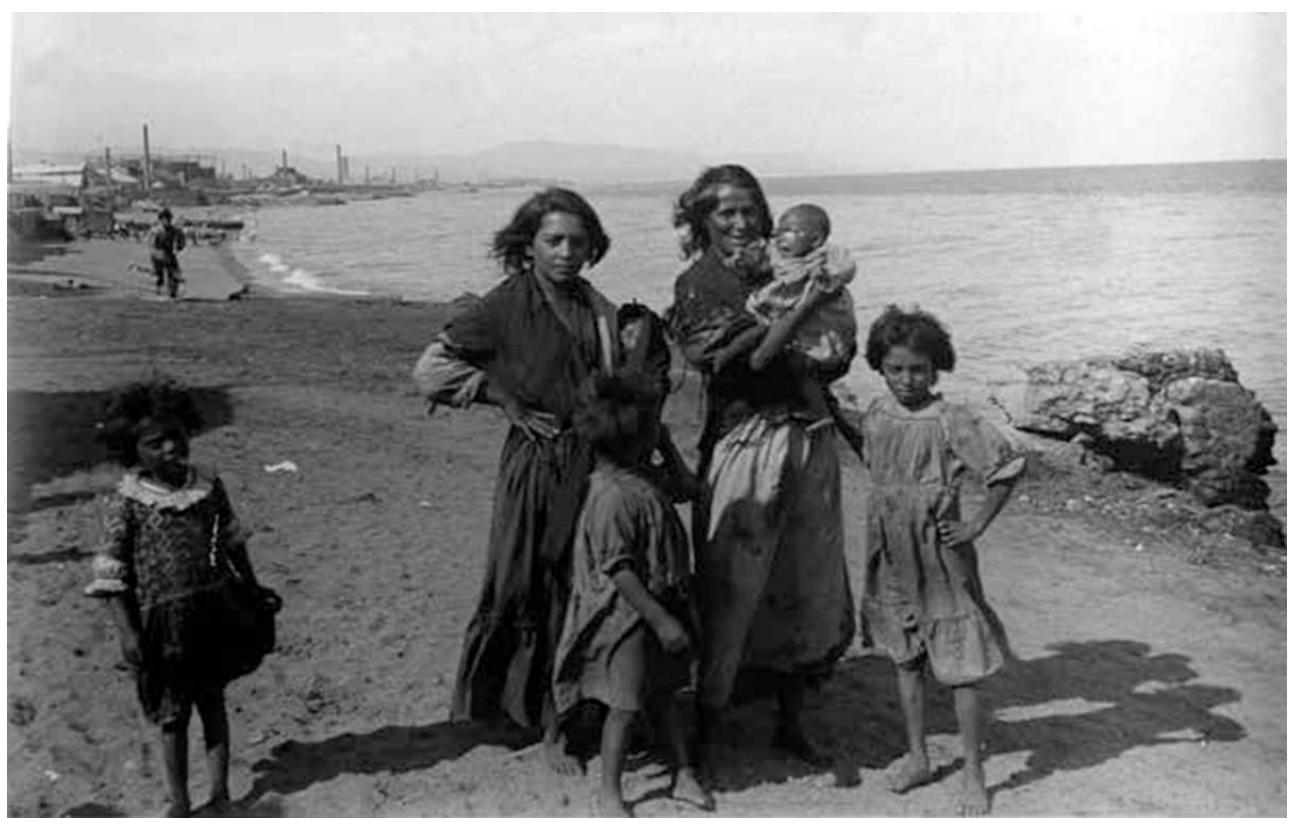

FOTO: FRANCESC LLORENS. ARCHIVO MUNICIPAL DE SANT FELIU DE GUÍXOLS 
Figura 8 : Familia en la playa de Montgat

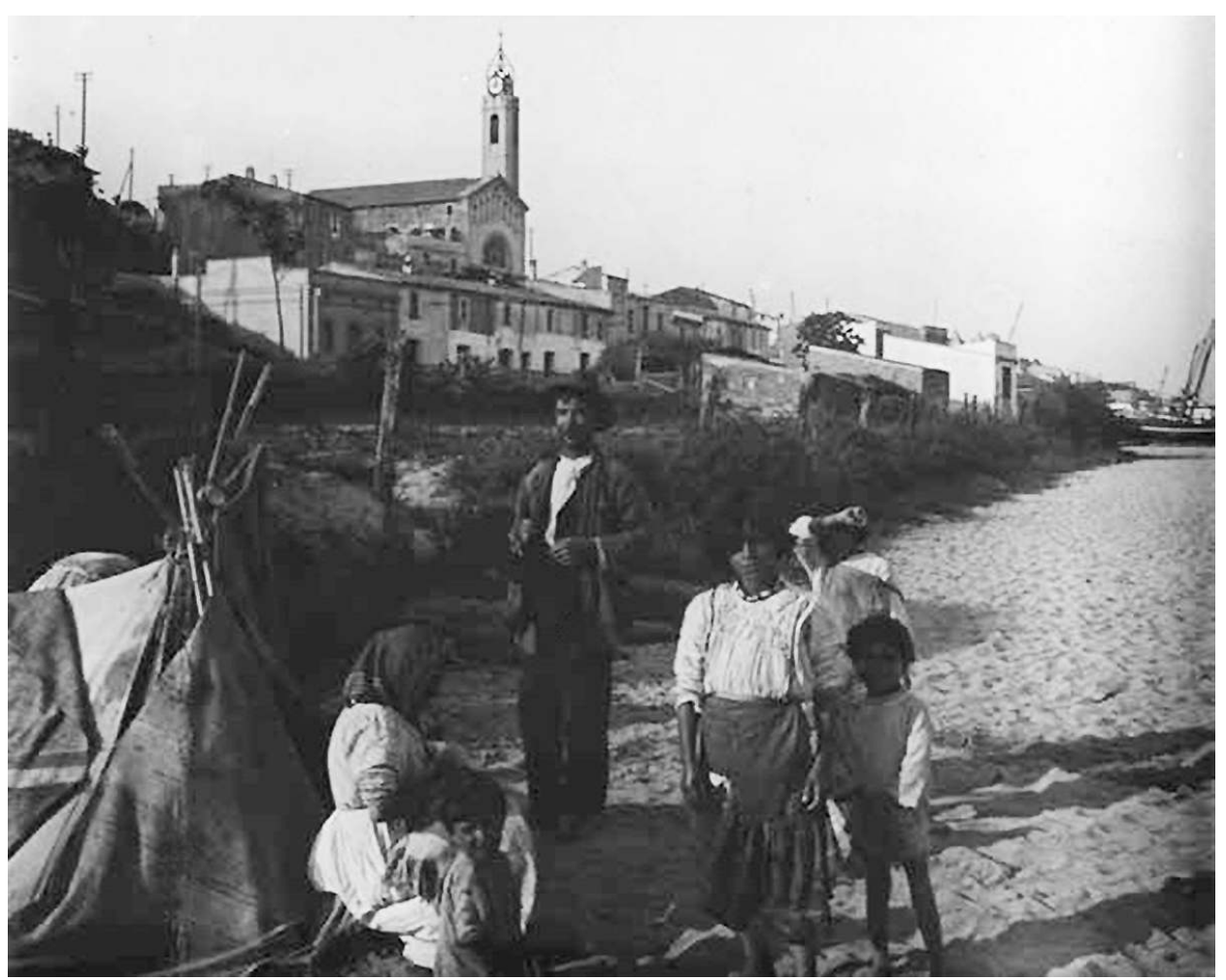

FOTO: FRANCESC LLORENS. ARCHIVO MUNICIPAL DE SANT FELIU DE GUÍXOLS ctante y nos presenta la mujer en una actitud más relajada e inmersa en la red de parentesco. Son fotografías que aportan realismo a las condiciones de vida de las mujeres que vivían cerca del mar. Nos podemos fijar en la indumentaria, en el hecho de que hay muchos niños y niñas, en la actitud aparentemente despreocupada. Otro aspecto interesante de las fotografías es la constatación de marginalidad que transmiten, en el sentido de que las protagonistas de las fotos parecen habitar en el margen de otra cosa. En la primera fotografía, vemos al fondo las chimeneas del barrio industrial de Poblenou de Barcelona. Lo primero que hay que hacer notar es el paralelismo con el dibujo del temporal de 1911, donde también podemos observar las chimeneas humeantes de una fábrica en el fondo de la imagen. Estas mujeres, por tanto, están en una playa que está al margen de una zona industrial y que es a la vez una zona marítima marginal de la gran ciudad.

Como hemos podido ver, las diversas imágenes de la mujer y el mar pueden presentar vínculos, paralelismos y solapamientos que son interesantes de contraponer. La diferencia radica en el abanico de condiciones vitales en los que están sumidas estas mujeres. 


\section{Conclusión} décadas de olvido por el uso casi exclusivamente turístico-recreativo del espacio costero ${ }^{10}$ . Actualmente, se restauran o reconstruyen embarcaciones de pesca artesanal de madera, como los laúdes de sardinal a vela latina, se musealizan los escasos edificios que han sobrevivido al desarrollo urbanístico vinculados a oficios de la pesca, como teñidores de redes o estaciones de salvamento, y se recrean operaciones desaparecidas en torno a la pesca, en el contexto de ferias y fiestas locales, como la subasta cantada de pescado al aire libre o la pesca con arte de playa. Todas estas iniciativas tienen una finalidad educativa y cultural. De todos modos, siguen siendo incompletas porqué no tienen en cuenta el rol de las mujeres en la sociedad que tratan de reconstruir patrimonialmente. Y cuando se tiene en cuenta, como es en el caso de las esculturas que recuerdan la presencia de la mujer en la sociedad tradicional, hemos visto que reconstruyen una imagen parcial y sesgada. En cambio, de todos los ámbitos de la recuperación patrimonio marítimo, uno de los que se debería tener más en cuenta es el que se ocupa del papel de las mujeres, por el rol central, para utilizar la acertada expresión de Sally Cole (1991), que ha desarrollado la mujer en estas comunidades.

a vinculadas a la pesca artesanal que desarrollaban las mujeres en las comunidades pesqueras fueron decayendo con la capitalización de la actividad que llevó a industrializar procesos manuales. Mientras tanto, las mujeres iban accediendo a espacios del mundo marítimo que durante muchos tenían vetados, como la marina mercante, la ingeniería naval, los trabajos portuarios, la alta competición deportiva naval, etc.

53

igualdad entre hombres y mujeres en el ámbito marítimo todavía está lejos de ser alcanzada, como señalaba Maria Damanaki en el texto mencionado en la introducción. Así mismo, el conocimiento y el reconocimiento sobre el rol de la mujer en las comunidades pesqueras tradicionales, como hemos visto aquí, todavía resulta escaso y sesgado. Al contraponer las distintas imágenes sobre la mujer y el mar en Cataluña hemos querido 
contribuir a situar mejor el rol de la mujer en las comunidades pesqueras tradicionales, entre la realidad y la representación.

\section{BIBLIOGRAFÍA}

Alberich N. 2001 - La feina d'en terra de la gent de mar: les remendadores de Cambrils. Quaderns de l'Institut Català d'Antropologia 15-16: 89-102.

Alegret J. L. 2006 - Etnologia de les societats marítimes: perspectives d'anàlisi, àmbits d'estudi i propostes de treball. Girona, Universitat de Girona, Càtedra d'Estudis Marítims, 23 p.

Alegret J. L. 1987 - Els armelladers de Palamós. Girona, Diputació de Girona, 254 p.

Alegret J. L. \& Carbonell E. 2014 - Revisiting the Coast: New Practices in Maritime Heritage. Girona, ICRPC, $212 \mathrm{p}$.

Benavent N. 1993 - La dona en l'àmbit pesquer de Vilanova i la Geltrú. Miscelllània Penedesenca 16 : 453-466.

Breton F., Lladó F. \& Badia A. 1992 - Femmes Pêcheurs et Femmes de Pêcheurs à la Barceloneta (Catalogne). Anthropologie Maritime 4 : 41-62.

Cáceres R. 1999 - Las mujeres en las sociedades pesqueras del estado espanyol. In : Actas del VIII Congreso de Antropología, Simposio III: Antropología de la Pesca (Santiago de Compostela, 20-24 septiembre, 1999). Santiago de Compostela, Federación de Asociaciones de Antropología del Estado Español (FAAEE) : 81-89.

Calvo L., Mañà J. \& Naranjo J. 1994 (Ed.) - Temps d'ahir. Arxiu d'Etnografia i Folklore de Catalunya 1915-1930. Barcelona, Fundació La Caixa, 133 p.

Carbonell E. 2006 - Josep Pla, el temps, la gent $i$ el paisatge. Una etnografia de l'Empordà franquejant la literatura. Barcelona, Edicions de 1984, 292 p.

Carbonell E. 2012 - El temporal de 1911 a Catalunya: La patrimonialització de les catàstrofes naturals. In : Alegret J. L. \& Carbonell E. (Ed.) La patrimonialització de la cultura marítima. Girona, Institut Català de Recerca en Patrimoni Cultural : 11-28.

Carbonell E. 2013 - Les tradicions marineres com a patrimoni inmaterial. Revista d'Etnologia de Catalunya 39 : 118-123.

Carbonell E. 2014 - Opportunities and Contradictions in Maritime Heritage and Small-scale Fishing. A Case Study of Catalonia. Collegium Antropologicum 38 (1) : 289-296.

Cole S. 1991 - Women of the praia: work and lives in a Portuguese coastal community. Princeton (N.J.), Princeton University Press, 208 p.

Comes G. 2009 - Les últimes remendadores a Baix a Mar. Torredembarra. Recull de treballs 10 : $39-469$.

Costa i Llobera M. 1982 - Les horacianes $i$ altres poemes. Barcelona, Edicions 62, 144 p. 
Dalla-Corte G. 1998 - Vida y muerte de una aventura en el Rio de la Plata, Jaime Alsina i Verjés, 1770/1836. Historia, Derecho y familia en la disolución del orden colonial. Tesis Doctoral. Universitat de Barcelona. En línea: http://hdl.handle.net/2445/62403

Frigolé J. 1999 - Llevarse la novia. Estudio comparativo de matrimonios consuetudinarios en Murcia y Andalucía. Bellaterra, UAB, 90 p.

Hastrup F. 2011 - Weathering the World. Recovery in the Wake of the Tsunami in a Tamil Fishing Village. Oxford, Berghan Books, 158 p.

Houseman M. 1990 - Le tabou du lapin chez les marins. Une spéculation structurale. Ethnologie Française 20 (2) : 125-142.

Marugán B. 2008 - Explorando algunas posibilidades de transformación. Recorrido de las mariscadoras gallegas hacia el reconocimiento social. In : Rodríguez P. (Ed.) Mujeres, trabajos y empleos en tiempos de globalización. Barcelona, Icària : 265-292.

Nadel Klein J. \& Lee Davis D. 1988 - To Work and To Weep: Women in Fishing Economies. St. John's, Nfld, Institute of Social and Economic Research, $320 \mathrm{p}$.

Pascual J. 1991 - Entre el mar y la tierra. Los pescadores artesanales canarios. Santa Cruz de Tenerife, Editorial Interinsular Canaria, $310 \mathrm{p}$.

Pla J. 1947 - Cadaqués. Barcelona, Editorial Juventud, 200 p.

Pla J. 1969 - Notes disperses. Barcelona, Destino, Obres complertes vol. 12, 577 p.

Pujol E. \& Carbonell E. 2009 - Records d’una dona de mar. Palamós, Fundació Promediterrània, 82 p.

Roig E. 1927 - La pesca a Catalunya. Barcelona, Barcino, 158 p.

Rubio-Ardanaz J. A. 2011 - La vida arrantzale en Santurtzi. Bilbao, Ediciones Beta III Milenio, 496 p.

Ruyra J. 2004 - Marines i boscatges. Barcelona, Selecta, 267 p.

Smith M. E. 1977 - Comments on the Heuristic Utility of Maritime Anthropology. The Maritime Anthropologist 1 (1) : 2-8.

Sol J. \& Jiménez J. 2005 - Els premianencs i el mar. Premià de Mar, Associació Bellamar, Centre d'Estudis Marítims, $160 \mathrm{p}$.

Soler J. 1996 - Rondalles mariners. Barcelona, Noray, 149 p.

Thompson P. 1985 - Women in the Fishing: The Roots of Power between the Sexes. Comparative Study in Society and History 27 (1) : 3-32.

Torra E. \& Carbonell E. 2015 - Les dones i el mar. Barcelona, Museu Marítim de Barcelona, 184 p.

Torry W. 1972 - Anthropology Studies in Hazardous Environment: Past Trends and New

Horizons. Current Anthropology 20 (3) : 517-540.

\section{NOTAS}

1. Pesca y acuicultura en Europa, n51, mayo 2011, página 11.

2. Pintura conservada en el Museo de Arte Reina Sofía de Madrid. Puede verse en el siguiente enlace: http://www.museoreinasofia.es/coleccion/obra/figura-finestra-figura-ventana (consulta: 22/09/2016)

3. Es difícil traducir este fragmento sin restarle fuerza poética. Una traducción literal podría ser: “Oí un gemido cerca de mi. Lo había lanzado aquella mujer que poco rato antes me había contado 
que tenía a toda su familia en el mar. Estaba inmóvil, estirada, como tiesa de frío, pálida, con los ojos sorprendidos. Su cabeza temblaba levemente y los dientes chasqueaban. Sus labios descoloridos repetían una palabra, siempre la misma: ¡Niñito... mi niñito!”

4. Conviene aclarar que este escritor y periodista escribía sus historias sobre los agricultores y pescadores catalanes desde una aproximación muy cercana a la etnografía, como traté de demostrar en mi tesis doctoral dedicada justamente a la dimensión etnográfica de la obra de Josep Pla (Carbonell 2006).

5. Traducción: "Comenzó una angustia general que desembocó en una tragedia oscura".

6. Ver: https://www.youtube.com/watch?v=BuayMcMiq3Q (consulta: 12/01/2016)

7. Ver: https://www.youtube.com/watch?v=Fa4vZ8h-PQI (consulta: 12/01/2016)

8. Traducción: "La mar yo aborrecía, mas ya la amo ahora / desde que allí tiene hospedaje el amor que me huyó. / No tengo en tierra ni padre ni madre, / mas él está aquí".

9. Traducción: "En estas orillas del Mediterráneo las chicas, incluso cuando ríen, tienen una punta de angustia y tristeza"

10. Me he ocupado de estos procesos de patrimonialización de la cultura marítima en otros trabajos. Ver: Carbonell 2013; Alegret, Carbonell 2014; Carbonell 2014.

\section{RESÚMENES}

En Cataluña, como en muchos países europeos y del mundo entero, históricamente las mujeres han desarrollado un papel muy relevante en las comunidades asentadas en el litoral, ocupándose específicamente de tareas como la comercialización del pescado, la industria conservera, la reparación y fabricación de artes de pesca o la gestión económica de los grupos domésticos. Sin embargo, durante el último tercio del siglo veinte se produce en Cataluña la capitalización de la actividad pesquera y las funciones que tradicionalmente realizaban las mujeres fueron progresivamente sustituidas por otros medios de trabajo mecanizado y las mujeres desaparecen de la esfera pública de la pesca artesanal. Lo que queda en el imaginario colectivo son las representaciones del rol de la mujer en la sociedad tradicional costera que nos ha llegado a través de la literatura, el arte y los cuentos populares. Estas representaciones transmiten la imagen de una mujer que afronta su destino, a menudo trágico, de manera pasiva, la mujer que espera con la mirada atenta y angustiada hacia el mar por donde debería volver el hombre. Frente a esta imagen trágica e impresionante, contrasta la imagen de la mujer que actúa, que trabaja, que gestiona sus oportunidades y que podemos observar sobre todo a través de las fotografías antiguas y los relatos etnográficos. En este artículo proponemos una revisión de las imágenes sobre las mujeres y el mar que podemos encontrar en Cataluña, tanto a través de las investigaciones etnográficas como de aquellas imágenes que nos han llegado a través de fotografíes, el arte y la literatura. Como afirmaba en 2011 la Comisaria Europea de Asuntos Marítimos y Pesca, Maria Damanaki, la igualdad entre el hombre y la mujer en el sector marítimo todavía está lejos de ser una realidad y esto puede observarse también a nivel de la representación de las mujeres en el imaginario colectivo. Este es al menos el caso de Cataluña expuesto en este artículo.

En Catalogne, comme dans beaucoup d'autres pays européens et du monde entier, les femmes ont, historiquement, développé un rôle très actifs dans les communautés côtières. Elles s'y sont insérées plus particulièrement par des tâches telles que la commercialisation du poisson, 
l'industrie de la conserverie, la réparation et la fabrication des agrès de pêche et la gestion économique des groupes domestiques. Cependant, avec la capitalisation de l'activité de pêche en Catalogne au cours du dernier tiers $\mathrm{du} \mathrm{xx}^{\mathrm{e}}$ siècle, les fonctions assumées par les femmes furent progressivement remplacés par d'autres moyens, généralement mécanisés. Les femmes disparaissent alors de la sphère publique de la pêche artisanale. Ce qui reste dans l'imaginaire collectif sont des représentations du rôle des femmes dans la société traditionnelle qui nous arrivent à travers la littérature et l'art. Ceux-ci nous transmettent l'image d'une femme qui fait face à son destin, souvent tragique, et de façon passive : la femme est en attente, avec ses enfants, le regard inquiet tourné vers la mer d'où devrait retourner les hommes. Face à cette image tragique et impressionnante, contraste l'image des femmes qui agissent, qui travaillent, qui gèrent différentes opportunités et qu'on peut retrouver surtout à travers des photographies anciennes et des récits ethnographiques. Dans cet article nous proposons une révision des images des femmes et la mer de Catalogne par la recherche ethnographique et par les images que nous offrent la littérature et l'art. Comme le disait en 2011 la Commissaire Européenne pour des affaires maritimes et de la pêche, Maria Damanaki, l'égalité des genres est encore loin d'être accomplie dans le secteur maritime, et c'est le cas avec la représentation des femmes dans l'imaginaire collectif, à tout le moins avec le cas de la Catalogne analysé dans cet article.

In Catalonia, as in many European countries and throughout the world, women have historically played a very important role in the coastal communities, dealing specifically with tasks such as the commercialization of fish, the fish canning industry, the repair and manufacture of fishing nets, and the management of domestic groups. However, during the last third of the twentieth century, a capitalization of fishing activity took place in Catalonia and the functions traditionally carried out by women were progressively replaced by other means of mechanized work. At this point, women disappeared from the public sphere of artisanal fishing. In the collective imagination only remains the representation of the role of women in traditional coastal society through literature, art and folklore. These representations convey the image of a woman who faces her fate, often tragically, passively; A woman who waits with an attentive and anguished look towards the sea, where his man should return. Faced with this tragic and impressive image, it contrasts the image of the woman who acts, who works, who manages her opportunities, as can observe through old photographs and ethnographic accounts. This paper proposes a review of the images of women and the sea that can be found in Catalonia, both through ethnographic research and the images that have come to us through photography, art and literature. As stated in 2011 by Maria Damanaki, the European Commissioner for Maritime Affairs and Fisheries, equality between men and women in the maritime sector is still far from being a reality. This can also be observed in the cultural representation of women and sea. This is, at least, the case of Catalonia exposed in this article.

\section{ÍNDICE}

Palabras claves: pesca artesanal, mujeres, Cataluña, imaginario colectivo

Keywords: artisanal fishing, women, Catalonia, collective imagination

Mots-clés: pêche artisanale, femmes, Catalogne, imaginaire collectif

\section{AUTOR}

\section{ELISEU CARBONELL}

Professeur d'anthropologie social 
e, Departament de Pedagogia, Universitat de Girona, 17071 Girona Catalogne (Espagne) 